\title{
Índice de Mobilidade Urbana Sustentável (IMUS) para os Aspectos Ambientais e Modos não Motorizados em Sinop-MT
}

\section{Index of Sustainable Urban Mobility (IMUS) for Environmental Aspects and Non-Motorized Modes in Sinop-MT}

${ }^{1}$ Lucas João Boter Ferraz, ${ }^{2}$ Alexandra Marsaro Cella, ${ }^{3}$ Renata Mansuelo Alves Domingos, ${ }^{4}$ Emeli Lalesca Aparecida da Guarda, ${ }^{5}$ João Carlos Machado Sanches

\begin{abstract}
${ }^{1}$ Engenheiro Civil - Universidade do Estado de Mato Grosso (lucasjbf@ hotmail.com) ${ }^{2}$ Mestranda em Arquitetura e Urbanismo no Programa de Arquitetura e Urbanismo - Universidade Federal de Santa Catarina (alexandramcella@gmail.com) ${ }^{3}$ Mestranda em Engenharia Civil no Programa de Engenharia Civil - Universidade Federal de Santa Catarina (mansuelo.alves@gmail.com) ${ }^{4}$ Doutoranda em Arquitetura e Urbanismo no Programa de Arquitetura e Urbanismo - Universidade Federal de Santa Catarina (emeliguarda@gmail.com) ${ }^{5}$ Professor Associado na Faculdade de Ciências Exatas - Universidade do Estado de Mato Grosso
\end{abstract} (sanches@unemat-net.br)

\begin{abstract}
RESUMO: O conceito de mobilidade urbana tem influência direta nas populações das cidades. O Índice de Mobilidade Urbana Sustentável (IMUS) é uma ferramenta de avaliação e diagnostico dos aspectos de mobilidade, proposto com o intuito de abranger as diversas áreas que esse tema possui. O índice possui uma estrutura composta por domínios, temas e indicadores, permitindo em sua aplicação uma análise parcial. Nesta pesquisa, buscou-se aplicar em Sinop o IMUS de maneira setorial sobre os domínios Aspectos Ambientais e Modos não Motorizados, que atingiram 40,7\% e 40,5\% da pontuação máxima, respectivamente. Esses números representam influências negativas na mobilidade urbana. $\mathrm{O}$ crescimento acentuado da frota de veículos motorizados, em ritmo muito acima do crescimento populacional e da implantação de obras de transportes reflete o desafio enfrentado atualmente no município, sendo necessárias soluções para que a tomada de ações seja efetiva. A partir dos resultados obtidos são feitas sugestões de melhorias para atender as exigências na área da mobilidade urbana, cada vez mais rígidas devido a sua crescente discussão.
\end{abstract}

Palavras Chave: Indicadores Urbanos. Sustentabilidade. Transporte Urbano.

ABSTRACT: The concept of urban mobility has a direct influence on city populations. The Index of Sustainable Urban Mobility (IMUS) is an instrument of evaluation and diagnosis of the mobility aspects, purposed with the aim to embrace the diverse areas that this topic has. The index has a structure composed by domains, themes and indicators, allowing a partial analysis in its application. In this research, was aimed to apply in Sinop the IMUS in a sectorial way over the domains Environmental Aspects and Non-Motorized Modes, which reached 40,7\% and $40,5 \%$ of the maximum score, respectively. The sharp growth of the fleet of motorized vehicles, at a rate much higher of the population growth and of the transportation constructions reflects the challenge faced currently in the city, being necessary solutions in order that decision-making be effective. From the obtained results there are suggestions made for improvements to attend the demands in the urban mobility area, increasingly rigid due to its crescent discussion.

Keywords: Urban Indicators. Sustainability. Urban Transportation.

\section{INTRODUÇÃO}

O crescimento acentuado dos centros urbanos observado nas últimas décadas traz consigo uma série de desafios ao desenvolvimento sustentável das cidades. Os problemas relativos à mobilidade vêm em grande parte de uma mudança no padrão de vida e mentalidade da população, que de certa maneira associou qualidade de vida à posse de automóveis particulares e atingindo tal objetivo, ocupou as ruas com seus veículos de maneira desenfreada, dificultando a própria mobilidade.

No Brasil, ocorreu um crescimento acentuado da frota de veículos, em ritmo muito superior ao da população. Em Sinop, Mato Grosso, local deste estudo, fica ainda mais evidente 
tal fenômeno. De um modo geral, é possível observar que ainda há o início de uma prática política que tenha uma visão para a sustentabilidade de mobilidade urbana, porém encontra como obstáculo a baixa aceitação popular dessas práticas.

Observa-se o recente surgimento da pressão governamental por meio de legislação como um outro fator influente no que se refere a mudanças. A Lei Federal 12587/12, conhecida por Lei da Mobilidade Urbana, determina que todos os municípios com população acima de vinte mil habitantes tenham e revisem periodicamente um plano de mobilidade urbana integrado ao plano diretor, como requisito para a captação de recursos para investimentos na área (BRASIL, 2012).

A necessidade da discussão da mobilidade urbana nos estudos sobre o desenvolvimento das cidades, levou a associação da sustentabilidade ao tópico, gerando um novo tema de estudos, a Mobilidade Urbana Sustentável (MUS). Tem-se a definição deste conceito pelo MCIDADES (2004), como o resultado da associação das políticas de transporte e circulação, baseado nas pessoas e não nos veículos, visando a acessibilidade, sustentabilidade, segurança e a otimização do espaço urbano de forma inclusiva socialmente.

Com a definição de tal conceito, houve a necessidade de se construir ferramentas para poder mensurar a MUS nos municípios. Costa (2008) apresentou a criação do Índice de Mobilidade Urbana Sustentável (IMUS), uma ferramenta que permite a avaliação e monitoramento da MUS dos municípios por meio do cálculo de indicadores, por sua vez agrupados em nove domínios, todos relativos à mobilidade urbana.

O objetivo desta pesquisa foi determinar o IMUS de maneira parcial, por meio do cálculo - e quando da inexistência de dados confiáveis, propor adaptações na metodologia para dois de seus domínios: Aspectos Ambientais e Modos não Motorizados, os quais têm maior peso na dimensão ambiental da mobilidade urbana. A pesquisa tem também a finalidade de propor soluções para problemas na mobilidade a serem identificados com base nos resultados atingidos, como ferramenta de monitoramento da ação de políticas da área.

\section{REFERENCIAL TEÓRICO}

O transporte sustentável é definido como a capacidade de satisfazer a necessidade de transporte atual sem comprometer as necessidades das gerações futuras (WCED, 1987 apud COSTA, 2008). Aliando tal definição com conceitos e iniciativas da mobilidade urbana sustentável desenvolvidos internacionalmente, em locais como Europa, Estados Unidos e Canadá, nos quais o estudo de ferramentas de avaliação do comportamento da MUS nas cidades é baseado em experiências realizadas há tempo considerável (COSTA, 2008), foi observada pela autora a necessidade de desenvolver uma ferramenta adequada no Brasil para o monitoramento da MUS, o que teve como resultado o IMUS.

\section{1 Índice de Mobilidade Urbana Sustentável}

O Índice de Mobilidade Urbana Sustentável, de Costa (2008), é um produto da associação estudos próprios da autora com outras bibliografias da área da mobilidade urbana. Sua pesquisa foi baseada na organização de workshops em cidades no país, abrangendo todas as regiões, colocando em discussão os tópicos que deveriam ser abordados no conceito de mobilidade urbana brasileiro. Assim, foram definidos os domínios, temas e indicadores necessários na composição do índice.

A estrutura do IMUS é determinada por uma hierarquia baseada na abrangência de suas partes componentes: são 9 domínios, divididos em 37 temas, que por sua vez são divididos em 87 indicadores. Cada indicador tem uma pontuação, denominada score, determinado pelo comportamento do dado avaliado dentro da respectiva tabela de valores de referência para o indicador. Cada score tem um peso dentro do grupo que o abrange, peso este que é disposto no 
Ferraz, Lucas João Boter.; et al; Índice de Mobilidade Urbana Sustentável (IMUS) para os Aspectos Ambientais e Modos não Motorizados em Sinop-MT. E\&S - Engineering and Science, 2020, 9:1.

sistema de cálculo do índice. A composição dos domínios abordados é apresentada nas Figura 1 e Figura 2.

Figura 1 - Conjunto de temas e indicadores para o domínio Aspectos Ambientais

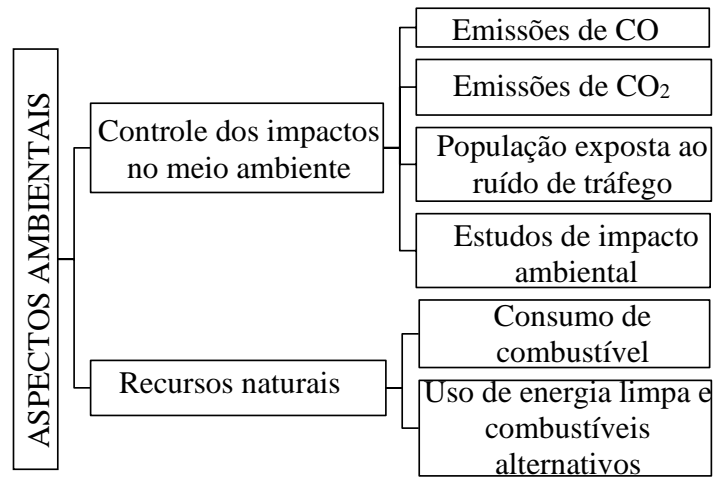

Fonte: Adaptado de Costa (2008).

Figura 2 - Conjunto de temas e indicadores para o domínio modos não motorizados

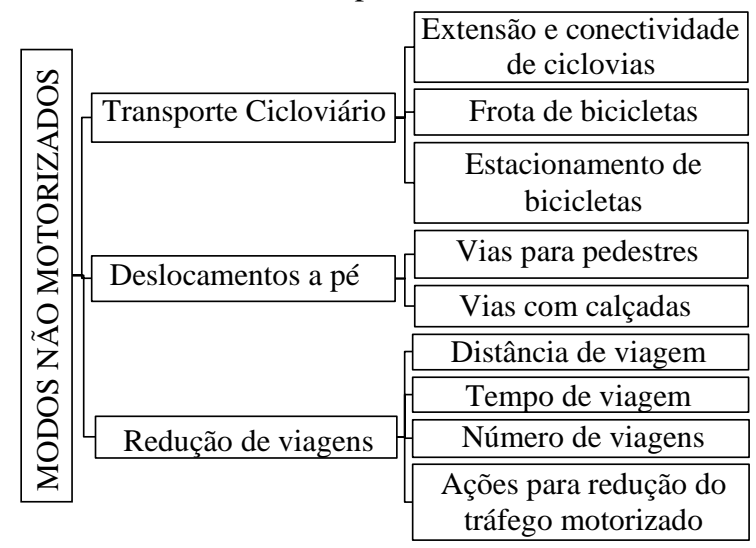

Fonte: Adaptado de Costa (2008).

Além do peso que o score de cada indicador tem sobre o tema, e consequentemente sobre o domínio e o índice geral, há também a distribuição setorial dos valores, entre as dimensões: social, econômica e ambiental, que compõem a base da mobilidade urbana sustentável. O número final do índice, assim como o valor referente a cada um dos indicadores, temas e domínios, é dado entre zero e um, adimensional.

A estrutura do índice permite a abrangência de um número determinado de domínios de modo a obter um índice parcial para os mesmos. Este caso configura o cálculo do IMUS setorial referente a domínios, o qual Costa (2008) define que pode ser calculado. O valor final da composição do índice geral, ou ainda, de domínios, permite a avaliação da mobilidade urbana da cidade de maneira geral ou com foco nos aspectos desejados, cumprindo o papel de ferramenta de auxílio para a gestão municipal. Por meio desse índice é possível definir quais áreas da mobilidade do município precisam de mais atenção quanto a investimentos e manutenções.

\subsection{Aplicação do IMUS em municípios brasileiros}

Após a elaboração da pesquisa de Costa (2008) em São Carlos, com o desenvolvimento e aplicação geral do índice, outros trabalhos foram feitos com o objetivo de calculá-lo em outros municípios, como: Goiânia-GO, de Abdala (2013), Uberlândia-MG, de Assunção (2012), Curitiba-PR, de Miranda (2010), Anápolis-GO, de Morais (2012) e Brasília-DF, de Pontes (2010). 
De acordo com Costa (2008), a existência de estudos envolvendo o cálculo do IMUS em diferentes municípios é importante para a revisão dos métodos de cálculo dos indicadores, com base nas adaptações a serem feitas para adequá-los na base de dados, assim como funcionar de parâmetro para atualização do índice em casos necessários, uma vez que as mudanças ocorridas em torno da mobilidade urbana podem alterar a influência de certos aspectos assim como pode colaborar para uma estabilidade. Além disso, o IMUS pode ser utilizado como uma ferramenta comparativa entre os diferentes municípios, apontando locais que são referência, de modo positivo ou negativo.

\section{METODOLOGIA}

A metodologia para cálculo dos indicadores apresentada neste trabalho foi desenvolvida por Costa (2008), que a descreveu por meio de um Guia de Indicadores. Em função do acesso as informações para a execução da metodologia, para a aplicação do IMUS em cada município, são válidas adaptações dentro de parâmetros estabelecidos pela autora, por meio de considerações sobre dados de base, fontes de dados e método de cálculo por indicador, permitindo alternativas para se obter os scores.

Alguns indicadores não têm a possibilidade de serem calculados devido a indisponibilidade de dados. Essa ocorrência pode ser observada nos trabalhos de composição geral do índice, como o de Morais (2012) e Pontes (2010). Quando houver essa situação, a recomendação prevista por Costa (2008) é de o score do indicador não calculado ser dado como vazio, com o peso deste sendo anulado do cálculo e o tema tendo os pesos redistribuídos com base nos indicadores que foram calculados.

Cada indicador possui uma tabela de valores de referência para determinação de seu respectivo score. $\mathrm{O}$ valor encontrado do dado necessário ao indicador é colocado entre os valores de referência para se ter o resultado. As tabelas dos valores de referência de cada indicador estão presentes em Costa (2008).

O ano de referência de dados adotado aqui é 2014, porém, como previsto por Costa (2008), no caso de não haver dados do ano de referência disponíveis, a última informação disponível será utilizada, desde que sua aplicação seja válida para o índice.

\subsection{Domínio: Aspectos Ambientais}

\subsubsection{Tema: Controle dos impactos no meio ambiente}

\section{a) Emissões de $\mathrm{CO}$}

Para o cálculo deste indicador, devido a inexistência de estudo da qualidade do ar, a alternativa de dados utilizados foram os dados de tabelas de fatores de emissão, elaboradas por órgãos ambientais, que as emitem baseadas nos dados de suas próprias análises e constituem uma referência válida para a caracterização da frota relacionada aos fatores de emissão, que por sua vez são influenciados por tipo de combustível dos veículos e ano de fabricação.

Para se fazer a estimativa das emissões de monóxido de carbono utilizou-se a tabela de fatores de emissão de gases dos veículos da Companhia Ambiental de Estado de São Paulo (CETESB, 2014), anexa no relatório de emissões veiculares. Para obter os dados referentes a Sinop, foram utilizadas as tabelas do Departamento Nacional de Trânsito, que trazem a frota por município e ano e município e tipo de combustível (DENATRAN, 2014). Para estimar a quantidade de veículos e ano, utilizou-se planilha eletrônica, por meio de médias ponderadas sobre a participação de cada tipo de combustível e de cada ano na frota, levando em consideração as observações da CETESB (2014), sobre o início da circulação de veículos flex em 2003 e término da produção de veículos movidos somente a etanol em 2006. 
Com estes dados, obteve-se uma emissão total de $\mathrm{CO}$ e, dividindo esse número pela frota correspondente (excluindo veículos movidos a diesel), obteve-se a emissão por veículo leve e motocicleta do município por quilômetro percorrido. O parâmetro adotado é a razão entre o fator de emissão geral encontrado por média ponderada na composição da frota e o fator limite de emissão atualizado do Programa de Controle da Poluição do Ar por Veículos Automotores (PROCONVE), e do Programa de Controle da Poluição do Ar por Ciclomotores, Motociclos e Veículos Similares (PROMOT), citados no relatório da CETESB, uma vez que não é possível obter a distância média percorrida anualmente pela indisponibilidade de dados. Vale ressaltar que a tabela foi atualizada em função das novas fases dos programas acima citados em vigência atualmente.

\section{b) Emissões de $\mathrm{CO}_{2}$}

Este indicador apresenta características muito semelhantes ao anterior, tendo o mesmo estudo como referência, porém com valores de fatores de emissão diferentes. O mesmo método de cálculo foi necessário também pela inexistência de um estudo específico da qualidade do ar e emissões veiculares para o município. Vale ressaltar que o limite de níveis da emissão de gases para veículos leves recomendados pela União Europeia, referência utilizada por Costa (2008), sofreu alterações desde o tempo da pesquisa da autora, portanto, o mesmo foi atualizado para o limite válido em 2014, de 130 g/km (EUROPA, 2007).

A utilização dessa referência de limite se faz necessária devido a política de limitar as emissões de $\mathrm{CO}_{2}$ do Brasil ainda estar em andamento e não ter regulamentação completamente definida. Outro ponto se refere a uma nova seleção de parte da frota para o cálculo, devido ao início da determinação de fatores de emissão de $\mathrm{CO}_{2}$ pela CETESB ter início apenas em 2002. Dessa maneira, a frota utilizada foi considerada apenas a registrada desse ano em diante, e novamente, desconsiderando os veículos movidos a diesel.

\section{c) População exposta ao ruído de tráfego}

Neste indicador foi realizado um levantamento em campo, com a medição dos níveis de ruído em dez pontos (como mostra a Figura 3) estabelecidos em função do tráfego, conciliados com uma considerável densidade populacional da área, obtida do mapa de densidade do IBGE (2010) para Sinop. Como referência foi utilizada e metodologia de Berrettini et al. (1998), estudo que foi a base para este indicador no cálculo do índice para São Carlos, de Costa (2008).

Figura 3 - Pontos de pesquisa selecionados com as vias destacadas.

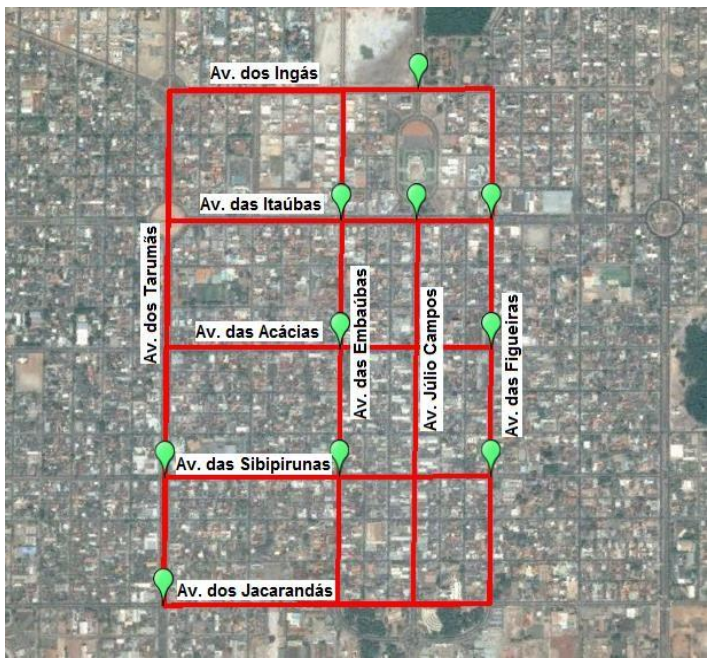


O método descrito neste artigo determina medições de 15 minutos em cada ponto durante horários de pico e por quatro dias úteis de uma semana típica no ano. Há orientações para se obter melhores resultados em uma abordagem do ponto de vista da acústica, que foram adotados, como posicionar o medidor em interseções de vias e apontar o microfone de maneira diagonal à interseção. Foi observada também a conformidade com as considerações da NBR 10151:2000, de avaliação de ruído em áreas habitadas, seguindo os requisitos para medição externa, como o posicionamento do equipamento, a 1,20 $\mathrm{m}$ do solo e a mais de $2 \mathrm{~m}$ de qualquer superfície refletora.

Mendonça et al. (2012) comprova que o tempo de medição de 5 minutos é estatisticamente válido em relação ao de 15 minutos, apresentando variações mínimas nas correlações, portanto foi possível adaptar o tempo de medição para 5 minutos por ponto. Morais (2012) também fez medições de 5 minutos por ponto em Anápolis. Como os horários de pico não são definidos por Berrettini et al. (1998), foram utilizados intervalos da pesquisa de Neto e Roza (2015), das 6:30h as 7:30h e 17:00h as 19:00h. A amostra da população é dada com base na densidade das áreas de influência do som de cada ponto, num raio de $250 \mathrm{~m}$ em cada local. As medições foram feitas em quatro dias úteis em uma semana típica do ano. O nível de pressão sonora equivalente contínuo (LAeq), dado em $\mathrm{dB}(\mathrm{A})$ (decibéis ponderados em $\mathrm{A}$ ), médio dos dias de medição em cada ponto é o dado utilizado para cálculo. "A" representa uma das curvas de ponderação do nível sonoro, relacionando o nível real com a sensibilidade da audição humana.

\section{d) Estudos de impacto ambiental}

Neste indicador, foi necessária a consulta a legislação municipal vigente e entrevista com gestora qualificada da Secretaria Municipal de Meio Ambiente, Ferri (2015), que forneceu as informações necessárias para obtenção do score deste indicador, que é qualitativo e não apresenta processo de cálculo, apenas observação dos requisitos existentes ou não.

\subsubsection{Tema: Recursos naturais}

\section{a) Consumo de combustível}

A composição deste indicador se deu por meio da razão entre consumo de gasolina em Sinop no ano de 2013, em litros, e a população total do município para o mesmo ano. A Agência Nacional do Petróleo (ANP, 2013), disponibiliza os dados da venda de combustível por município feitas pelas distribuidoras nos últimos anos. A quantidade de litros vendida neste ano referido, obtida nesta relação, foi utilizada e dividida pelo número de habitantes do município no ano, dado pelo IBGE (2013).

\section{b) Uso de energia limpa e combustíveis alternativos}

Este indicador constitui uma relação entre o transporte público e sustentabilidade. Em razão da ausência do levantamento necessário em Sinop, os dados foram obtidos por consulta com gestor da concessionária responsável pelo transporte público da cidade, Moraes (2015). Porém, o dado de obtenção possível foi referente apenas aos veículos de transporte público. Sobre os veículos de transporte semi-público, representados em sua maioria por táxis, não há dados disponíveis, visto que a associação de taxistas da cidade não se encontra em total atividade, segundo a Secretaria Municipal de Trânsito e Transporte Urbano, Franke (2015). 


\subsection{Domínio: Modos não motorizados}

\subsubsection{Tema: Transporte cicloviário}

\section{a) Extensão e conectividade de ciclovias}

Este indicador foi determinado por meio de levantamento de campo sobre a área efetivamente urbanizada de Sinop. Esta área foi delimitada pelos bairros do município que se encontram atualmente consolidados e com infraestrutura urbana básica, com serviços à população. A partir disso, a marcação dos locais com ciclovias foi feita sobre o mapa da cidade em software de desenho assistido por computador. Para a determinação dessa área foram excluídas áreas de preservação ambiental, e também de condomínios fechados, as quais não permitem acesso da população geral. Dessa forma, foi possível determinar as ciclovias dentro da cidade e localizá-las, assim como obter suas extensões. Para o conceito de conectividade, neste indicador foi adotada a conexão (ou ausência desta) entre as ciclovias, sendo realizada de maneira análoga no indicador Vias para Pedestres.

\section{b) Frota de bicicletas}

Neste indicador, foi utilizado para cálculo a estimativa da Secretaria Municipal de Trânsito e Transporte Urbano, Franke (2015) para 2014, por meio de entrevista com a gestora do órgão. $\mathrm{Na}$ ausência de levantamento adequado desse número, e pelo método de coletar o número de bicicletas comercializadas no município adotando-se o período dos últimos sete anos não se mostrando viável pela dificuldade em reunir os números de todos os fornecedores, Costa (2008) cita tal adaptação no guia de indicadores.

\section{c) Estacionamento de bicicletas}

Para este indicador, o dado foi coletado por meio de levantamento em campo. Como é referente ao estacionamento de bicicletas em terminais de transporte público e há apenas um terminal na cidade, não foram necessárias outras formas de obtenção de dados.

\subsubsection{Tema: Deslocamentos a pé}

a) Vias para pedestres

Foi realizado levantamento em campo dos locais que apresentam vias exclusivas ou preferenciais para pedestres, com posterior locação destes no mapa da área efetivamente urbanizada no município e medição da extensão de tais vias em software de desenho assistido por computador.

\section{b) Vias com calçadas}

Obteve-se informações não aplicáveis para este indicador. Não há um dado de extensão total dos lotes com calçadas no município, mesmo pela tentativa com o departamento de cadastro imobiliário da cidade.

Outros métodos se apresentaram inviáveis: levantamento em campo, pela dimensão deste com ausência de equipe; visualização por software de informações geográficas, pela dificuldade em visualizar o total de calçadas por imagens aéreas. Portanto, esse indicador não foi calculado. Assim, o indicador é dado como vazio e os pesos dentro do tema são redistribuídos em função dos indicadores calculados. 


\subsubsection{Tema: Redução de viagens}

Neste tema, há três indicadores que baseiam-se em dados de pesquisa de origem/destino, não existente em Sinop, estabelecendo um obstáculo no cálculo deste indicador.

Porém, há como utilizar dados de estudos de mobilidade nacionais para o fim de compor uma estimativa para este dado. A ANTP (Associação Nacional de Transportes Públicos) desenvolveu um estudo sobre a mobilidade urbana no Brasil, por meio do Sistema de Informações da Mobilidade Urbana (SI/ANTP), do qual 438 municípios fazem parte, incluindo Sinop. O estudo foi realizado com base nos dados obtidos por coleta de dados com a administração das cidades e órgãos de trânsito regionais em 2013, gerando o Relatório Geral da associação neste referido ano, publicado em 2015 (ANTP, 2015). O sistema relaciona os municípios que apresentavam população igual ou superior a 60 mil habitantes em 2003.

Neste relatório constam informações gerais sobre a mobilidade urbana dos municípios componentes, com levantamentos sobre viagens urbanas, custos da mobilidade, divisão modal, entre outras. As cidades são divididas em faixas de população e, de acordo com dados do IBGE (2013), no ano de elaboração do relatório, Sinop apresentava população entre 100 e 250 mil habitantes, sendo incluído, portanto, nesta faixa para a retirada de dados necessários aos indicadores pertinentes.

\section{a) Distância de viagem}

Neste indicador, foi observado o Relatório Geral 2013 da ANTP (ANTP, 2015) para a obtenção de informações. Para o cálculo do indicador, utilizou-se os números contidos no relatório, de distâncias médias percorridas por viagem para os diferentes modos. Posteriormente, fez-se uma média ponderada das distâncias multiplicando os valores pela participação modal de cada modo analisado, da mesma faixa de população, que consta no mesmo relatório.

\section{b) Tempo de viagem}

De maneira semelhante ao indicador anterior, os dados de referência foram obtidos do Relatório Geral 2013 da ANTP (ANTP, 2015). Utilizou-se os números de tempo médio de viagem do relatório e fez-se uma média ponderada com a distribuição modal dos municípios da mesma faixa de população para obter o tempo médio para todos os modos de transporte.

\section{c) Número de viagens}

Assim como nos dois indicadores anteriores, este indicador teve como base os dados do Relatório Geral 2013 da ANTP (ANTP, 2015). A informação utilizada vem dos números componentes do relatório, apresentados de forma direta.

\section{d) Ações para redução do tráfego motorizado}

As informações coletadas para este indicador foram obtidas por meio de entrevista com a gestora da Secretaria Municipal de Trânsito e Transporte urbano, Franke (2015), que esclareceu quais as ações (ou ausências destas) implantadas no município para a redução do tráfego motorizado. 


\subsection{Método de Cálculo do IMUS setorial}

O IMUS setorial (IMUS ) é uma forma de se obter a pontuação por domínios. Os valores que definem tal pontuação vêm do somatório dos produtos entre valores encontrados dos temas e indicadores e seus respectivos pesos, sendo todos coeficientes adimensionais. A Equação 1 apresenta o cálculo, onde: o peso do tema referente ao indicador " $\mathrm{i}$ " é $\mathrm{w}_{\mathrm{i}}^{\mathrm{T}}$, o peso do indicador "i” é $\mathrm{w}_{\mathrm{i}}^{\mathrm{I}}$ e o score do indicador "ij" é $\mathrm{x}_{\mathrm{i}}$.

$$
\operatorname{IMUS}_{\mathrm{S}}=\sum_{\mathrm{i}=1}^{\mathrm{n}} \mathrm{w}_{\mathrm{i}}^{\mathrm{T}} \cdot \mathrm{w}_{\mathrm{i}}^{\mathrm{I}} \cdot \mathrm{x}_{\mathrm{i}}
$$

Dentro de cada tema, o peso das dimensões traz a representatividade do item em relação a estas na MUS: social, econômica e ambiental. É uma maneira de se observar que proporções esses ramos tem na composição do tema. Na Tabela 1 pode-se observar os pesos das dimensões nos temas abordados, e o peso dos indicadores distribuído de acordo com o que foi calculado nesta pesquisa.

Tabela 1 - Pesos das dimensões, temas e indicadores

\begin{tabular}{|c|c|c|c|c|c|c|c|c|c|c|c|}
\hline \multicolumn{6}{|c|}{ Domínio: Aspectos Ambientais } & \multicolumn{6}{|c|}{ Domínio: Modos não Motorizados } \\
\hline \multicolumn{3}{|c|}{ Tema } & Peso & Indicador & Peso & \multicolumn{3}{|c|}{ Tema } & Peso & Indicador & Peso \\
\hline \multirow{4}{*}{\multicolumn{3}{|c|}{$\begin{array}{l}\text { Controle dos } \\
\text { impactos no meio } \\
\text { ambiente }\end{array}$}} & \multirow{6}{*}{0,52} & Emissões de CO & 0,25 & \multirow{3}{*}{\multicolumn{3}{|c|}{$\begin{array}{l}\text { Transporte } \\
\text { cicloviário }\end{array}$}} & \multirow{5}{*}{0,31} & Extensão e conectividade & \multirow{2}{*}{0,33} \\
\hline & & & & Emissões de CO2 & 0,25 & & & & & de ciclovias & \\
\hline & & & & \multirow{2}{*}{$\begin{array}{l}\text { População exposta ao } \\
\text { ruído de trafego }\end{array}$} & \multirow{2}{*}{0,25} & & & & & Frota de bicicletas & 0,33 \\
\hline & & & & & & \multirow{2}{*}{0,32} & \multirow{2}{*}{0,29} & \multirow{2}{*}{0,39} & & Estacionamento de & \multirow{2}{*}{0,33} \\
\hline \multirow{2}{*}{0,29} & \multirow{2}{*}{0,28} & \multirow{2}{*}{0,43} & & \multirow{2}{*}{$\begin{array}{c}\text { Estudos de impacto } \\
\text { ambiental }\end{array}$} & \multirow{2}{*}{0,25} & & & & & bicicletas & \\
\hline & & & & & & \multicolumn{3}{|c|}{ Deslocamentos a pé } & \multirow{2}{*}{0,34} & Vias para pedestres & 1,00 \\
\hline \multicolumn{3}{|c|}{ Recurs os naturais } & \multirow{3}{*}{0,48} & Consumo de combustível & 0,50 & 0,33 & 0,28 & 0,39 & & Vias com calçadas & - \\
\hline \multirow[b]{2}{*}{0,26} & \multirow[b]{2}{*}{0,32} & \multirow{2}{*}{0,42} & & Uso de energia limpa e & \multirow[b]{2}{*}{0,50} & \multirow{3}{*}{\multicolumn{3}{|c|}{ Redução de viagens }} & \multirow{4}{*}{0,35} & Distancia de viagem & 0,25 \\
\hline & & & & combustíveis alternativos & & & & & & Tempo de viagem & 0,25 \\
\hline & & & & & & & & & & Número de viagens & 0,25 \\
\hline \multicolumn{3}{|c|}{$\begin{array}{c}\text { Social } \\
\text { Economica } \\
\text { Ambiental }\end{array}$} & & & & 0,28 & 0,32 & 0,40 & & $\begin{array}{l}\text { Ações para redução do } \\
\text { tráfego motorizado }\end{array}$ & 0,25 \\
\hline
\end{tabular}

\section{RESULTADOS E DISCUSSÕES}

\subsection{Resultados para o Domínio Aspectos Ambientais}

4.1.1 Resultados para o tema: Controle dos impactos no meio ambiente

a) Emissões de CO

O fator de emissão médio ponderado de $\mathrm{CO}$ por motocicletas encontrado na planilha com os dados do DENATRAN (2014) foi de 4,58 g/km, e por automóveis $1,84 \mathrm{~g} / \mathrm{km}$. Multiplicando-se esses valores pelas respectivas frotas, de 26165 motocicletas e 30555 automóveis, e ponderando tais números de frota pelo fator limite de emissão para cada tipo de veículo (2,0 g/km para motocicletas e $1,3 \mathrm{~g} / \mathrm{km}$ para automóveis), obteve-se o fator geral médio de $3,1 \mathrm{~g} / \mathrm{km}$ em emissão e limite de $1,62 \mathrm{~g} / \mathrm{km}$, configurando uma emissão $91,1 \%$ maior que o limite, com score 0,09 .

\section{b) Emissões de $\mathrm{CO} 2$}

De maneira análoga ao indicador anterior, porém com o cálculo apenas para automóveis, foi encontrado o fator médio de emissão de $187,95 \mathrm{~g} / \mathrm{km}$, ponderado por ano e tipo de combustível aplicado na frota. o fator encontrado excede em $44,6 \%$ o limite de $130 \mathrm{~g} / \mathrm{km}$, estabelecendo o score de 0,55 . 


\section{c) População exposta ao ruído de tráfego}

A amostra da população residente na área onde o ruído medido nos pontos de coleta tem influência, foi de 4882 habitantes, de acordo com o mapa de densidade populacional do censo do IBGE (2010). Os pontos foram escolhidos em função do tráfego e por haver considerável população trabalhando nos comércios da área central da cidade, também exposta ao ruído. Os níveis de ruído médios dos 4 dias de medição em $\mathrm{dB}(\mathrm{A})$ (LAeq) nos pontos são relacionados com o parâmetro limite descrito por Costa (2008), apresentados na Tabela 2 deste trabalho.

Tabela 2 - Níveis de ruído em $\mathrm{dB}(\mathrm{A})$ nos pontos de medição

\begin{tabular}{|c|c|c|}
\hline Ponto & Local & LAeq \\
\hline 1 & Av. Júlio Campos com Av. dos Ingás & 71,13 \\
\hline 2 & Av. das Itaúbas com Av. das Figueiras & 71,53 \\
\hline 3 & Av. Júlio Campos com Av. das Itaúbas & 70,90 \\
\hline 4 & Av. das Itaúbas com Av. das Embaúbas & 72,61 \\
\hline 5 & Av. das Embaúbas com Av. das Acácias & 70,99 \\
\hline 6 & Av. das Figueiras com Av. das Acácias & 68,98 \\
\hline 7 & Av. das Figueiras com Av. das Sibipirunas & 70,59 \\
\hline 8 & Av. das Embaúbas com Av. das Sibipirunas & 71,10 \\
\hline 9 & Av. dos Tarumãs com Av. das Sibipirunas & 73,37 \\
\hline 10 & Av. dos Tarumãs com Av. dos Jacarandás & 71,96 \\
\hline
\end{tabular}

Em todos os pontos, o nível foi superior a $65 \mathrm{~dB}(\mathrm{~A})$, portanto, $100 \%$ da população da amostra é afetada. Porém, Costa (2008) expõe que a influência do ruído sobre a amostra não pode ser considerada na totalidade da área urbana, e neste caso, a população urbana fora da área de estudo não pode ser considerada exposta a ruído excessivo. A população da área abordada corresponde a 3,85\% da população de Sinop, de 126.817 habitantes (IBGE, 2014). Portanto, o score obtido foi 0,96 , com base na área em que foi possível realizar o levantamento para este indicador.

\section{d) Estudos de impacto ambiental}

Segundo a Secretaria Municipal de Meio Ambiente, Ferri (2015), o município não exige qualquer estudo ou medida mitigadora sobre impactos dos sistemas de transportes e mobilidade urbana, apenas faz licenciamentos. Portanto, obtém-se um score igual a 0,00.

\subsubsection{Resultados para o tema: Recursos naturais}

a) Consumo de combustível

Os dados de venda de gasolina pelas distribuidoras nos municípios (ANP, 2013), estabelecem o volume de 31.114.320 L para este ano citado. A população do município em 2013 segundo a estimativa do IBGE era de 123.634 habitantes. A relação que obtemos é de $251,66 \mathrm{~L} / \mathrm{habitante} /$ ano e o score atinge 0,83 .

\section{b) Uso de energia limpa e combustíveis alternativos}

Segundo gestor da concessionária responsável pelo transporte coletivo do município (MORAES, 2015), não há veículos de transporte público no município que utilizem combustíveis limpos ou alternativos. Portanto, a porcentagem da frota de transporte público é de $0 \%$, então, o score é 0,00 . 
Ferraz, Lucas João Boter.; et al; Índice de Mobilidade Urbana Sustentável (IMUS) para os Aspectos Ambientais e Modos não Motorizados em Sinop-MT. E\&S - Engineering and Science, 2020, 9:1.

\subsection{Análise dos resultados do domínio Aspectos Ambientais}

A Tabela 3 apresenta os valores dos resultados do domínio Aspectos Ambientais obtidos para Sinop e dos municípios das outras aplicações do IMUS.

Tabela 3 - Resultados dos indicadores do domínio: Aspectos Ambientais

\begin{tabular}{cccccccc}
\hline Indicador & $\begin{array}{c}\text { São Carlos } \\
(\mathrm{SP})\end{array}$ & $\begin{array}{c}\text { Goiânia } \\
(\mathrm{GO})\end{array}$ & $\begin{array}{c}\text { Uberlândia } \\
(\mathrm{MG})\end{array}$ & $\begin{array}{c}\text { Curitiba } \\
(\mathrm{PR})\end{array}$ & $\begin{array}{c}\text { Anápolis } \\
(\mathrm{GO})\end{array}$ & $\begin{array}{c}\text { Brasília } \\
(\mathrm{DF})\end{array}$ & $\begin{array}{c}\text { Sinop } \\
(\mathrm{MT})\end{array}$ \\
\hline $\begin{array}{c}\text { Emissões de CO } \\
\text { Emissões de CO2 }\end{array}$ & 0,00 & 0,00 & 0,50 & Vazio & Vazio & Vazio & 0,09 \\
$\begin{array}{c}\text { População exposta ao } \\
\text { ruído de tráfego }\end{array}$ & 0,80 & 0,76 & 0,94 & 0,96 & 0,76 & Vazio & 0,96 \\
$\begin{array}{c}\text { Estudos de impacto } \\
\text { ambiental }\end{array}$ & 1,00 & 1,00 & 1,00 & 1,00 & 0,25 & 0,75 & 0,00 \\
\hline $\begin{array}{c}\text { Consumo de combustível } \\
\text { Uso de energia limpa e }\end{array}$ & 0,86 & 0,83 & 0,94 & 0,99 & 0,00 & 0,68 & 0,83 \\
combustíveis alternativos & 0,17 & 0,00 & 0,52 & 0,35 & 0,49 & 0,01 & 0,00 \\
\hline Domínio & $\mathbf{0 , 5 8 4}$ & $\mathbf{0 , 5 5 8}$ & $\mathbf{0 , 7 3 3}$ & $\mathbf{0 , 8 3 1}$ & $\mathbf{0 , 3 8 0}$ & $\mathbf{0 , 5 5 6}$ & $\mathbf{0 , 4 0 7}$ \\
\hline
\end{tabular}

Fonte: Abdala (2013), Assunção (2012), Costa (2008), Miranda (2010), Pontes (2010).

Nos indicadores Emissões de $\mathrm{CO}$ e Emissões de $\mathrm{CO}_{2}$, os valores encontrados para Sinop apresentam compatibilidade considerável com os outros municípios nos scores, comprovando que o método de cálculo utilizando a composição da frota e relatório de emissões veiculares apresenta certa viabilidade, mesmo que 3 municípios da bibliografia consultada apresentem resultados vazios devido a indisponibilidade de dados.

Controlar as emissões de $\mathrm{CO}$ representa um desafio em todos os municípios. Mesmo que a frota tenha maior participação de veículos com fabricação recente, a redução dos limites de emissão e participação de veículos antigos na frota contribuem negativamente para o indicador. $\mathrm{O}$ baixo valor obtido para Emissões de $\mathrm{CO}_{2}$ em Sinop é relativo à atualização do fator limite de emissão adotado da União Europeia.

A pontuação em População Exposta ao Ruído de Tráfego apresentou disparidade em relação às outras, que se deu devido ao tamanho e local da amostra (com foco na área central), visto que nos outros municípios foram utilizadas pesquisas de grande abrangência da área urbanizada, com dados institucionais e de bibliografias prévias, exceto em Anápolis, que teve levantamento próprio. O score de Sinop mostra que a área central da cidade, de um modo geral, possui poluição sonora devido ao tráfego, discussão que poderia ser aprimorada por meio de levantamento mais extenso nas diferentes zonas da cidade. Para a composição do score, seguindo o método de cálculo de Costa (2008) e levando-se em consideração a disponibilidade de tempo e equipamentos, foram adotados pontos críticos do trânsito, em interseções de avenidas de maior atividade comercial.

O resultado de Estudos de Impacto Ambiental reflete uma necessidade de desenvolvimento das políticas municipais na área ambiental, atualmente pouco exigentes, o que pode ser justificado pela idade e recente crescimento demográfico de Sinop. Tal necessidade fica ainda mais evidente se comparadas com Sinop as pontuações dos outros trabalhos.

Sobre o consumo de combustível, o valor encontrado em Sinop, é alto, mas aproximase da média das outras cidades. A malha viária municipal ainda não apresenta grandes distâncias de trajeto para os habitantes, sem grande consumo de combustível nas viagens e contribuindo positivamente para o score. No transporte público observa-se que a ausência de alternativas para redução do consumo de combustíveis fósseis reflete uma falta de preocupação da administração, conforme o resultado de Uso de Energia Limpa e Combustíveis alternativos, enquanto observa-se que os outros municípios consultados já apresentam um encaminhamento de soluções neste quesito. 
Ferraz, Lucas João Boter.; et al; Índice de Mobilidade Urbana Sustentável (IMUS) para os Aspectos Ambientais e Modos não Motorizados em Sinop-MT. E\&S - Engineering and Science, 2020, 9:1.

\subsection{Resultados para o Domínio: Modos não motorizados}

\subsubsection{Resultados para o tema: Transporte cicloviário}

a) Extensão e conectividade de ciclovias

Atualmente, Sinop conta com três ciclovias: da Avenida dos Tarumãs, da Avenida da Itaúbas e no início da rodovia MT-140. A extensão total, das três combinadas, é de 7,66 km, e não há interligação entre elas, o que reflete uma conectividade nula, considerada como baixa. O sistema viário total da cidade encontrado é de $919,66 \mathrm{~km}$. A relação da extensão de ciclovias sobre o sistema viário total é de 0,0083 , ou $0,83 \%$, assim o score atinge 0,25 .

\section{b) Frota de bicicletas}

Segundo estimativa da Secretaria de Trânsito e Transporte Urbano de Sinop, Franke (2015), a frota de bicicletas no município em 2014 era de 60.000 unidades. Relacionando com a estimativa de população de Sinop (IBGE, 2014), de 126.817 habitantes, temos: 0,473 bicicleta por habitante, ou 47,3 bicicletas por 100 habitantes, constituindo um score igual a 1,00.

c) Estacionamento de bicicletas

No único terminal de transporte público existente na cidade, não há estacionamento de bicicletas disponível para a população. Com $0 \%$ dos terminais com estacionamento de bicicletas, o score é igual a 0,00 .

\subsubsection{Resultados para o tema: Deslocamentos a pé \\ a) Vias para pedestres}

Sinop conta hoje com um local de via especial para pedestres, na Avenida das Itaúbas, com extensão de 2,02 km. Evidentemente, não há conexão com outras vias do mesmo tipo, por ser única. A relação sobre o sistema viário total é de $0,22 \%$, por isso, o score é 0,25 .

\section{b) Vias com calçadas}

Indicador não calculado devido a inexistência de dados adequados, não foi possível adaptar o cálculo sobre as informações encontradas, que apresentaram inconsistência. Considera-se vazio.

\subsubsection{Resultados para o tema: Redução de viagens}

a) Distância de viagem

A aproximação feita para se determinar o resultado deste indicador consistiu na aplicação das distâncias médias de viagem na distribuição modal do Relatório Geral 2013 da ANTP. As distâncias médias de viagem são de 13,3 km para transporte coletivo, que corresponde a $25,5 \%$ da distribuição modal; $4,4 \mathrm{~km}$ para transporte individual motorizado, correspondendo a $26,5 \%$ da distribuição modal; e $1,7 \mathrm{~km}$ para transporte não motorizado correspondendo a $48 \%$ da distribuição modal. Por meio de média ponderada, obteve-se a média de $5,37 \mathrm{~km}$ por viagem, que atinge score igual a 0,58 . 
Ferraz, Lucas João Boter.; et al; Índice de Mobilidade Urbana Sustentável (IMUS) para os Aspectos Ambientais e Modos não Motorizados em Sinop-MT. E\&S - Engineering and Science, 2020, 9:1.

\section{b) Tempo de viagem}

De maneira análoga ao indicador anterior, utilizando os tempos médios por modo e distribuição modal dos municípios da faixa de habitantes adequada do Relatório da ANTP (ANTP, 2013), com 35 minutos para transporte coletivo, 8 minutos para transporte individual motorizado e 16 minutos para transporte não motorizado, obteve-se o tempo médio de viagem de 18,73 minutos, ou 18 minutos e 44 segundos. O score obtido é 1,00.

\section{c) Número de viagens}

Sem a necessidade de cálculo e utilizando apenas a referência do Relatório da ANTP, temos uma média de 1,2 viagens por habitante por dia, compondo um score de 0,60.

\section{d) Ações para redução do tráfego motorizado}

Segundo entrevista com a gestora da Secretaria Municipal de Trânsito e Transporte Urbano de Sinop, Franke (2015), não há atualmente a vigência de nenhuma ação para desincentivar o uso do automóvel, apenas para incentivar o uso de modos não motorizados, sendo esta ação recente. Portanto, o score para o indicador é 0,00 .

\subsection{Avaliação dos resultados do domínio modos não motorizados}

A Tabela 4 apresenta os valores dos resultados do domínio Modos não motorizados obtidos para Sinop e os municípios das outras aplicações do IMUS citadas anteriormente.

Tabela 4 - Resultados dos indicadores do domínio Modos não motorizados

\begin{tabular}{cccccccc}
\hline Indicador & $\begin{array}{c}\text { São Carlos } \\
(\mathrm{SP})\end{array}$ & $\begin{array}{c}\text { Goiânia } \\
(\mathrm{GO})\end{array}$ & $\begin{array}{c}\text { Uberlândia } \\
(\mathrm{MG})\end{array}$ & $\begin{array}{c}\text { Curitiba } \\
(\mathrm{PR})\end{array}$ & $\begin{array}{c}\text { Anápolis } \\
(\mathrm{GO})\end{array}$ & $\begin{array}{c}\text { Brasília } \\
(\mathrm{DF})\end{array}$ & $\begin{array}{c}\text { Sinop } \\
(\mathrm{MT})\end{array}$ \\
\hline $\begin{array}{c}\text { Extensão e conectividade } \\
\text { de ciclovias }\end{array}$ & 0,25 & 0,25 & 0,00 & 0,25 & 0,25 & 0,15 & 0,25 \\
$\begin{array}{c}\text { Frota de bicicletas } \\
\text { Estacionamento de bicicletas }\end{array}$ & 0,33 & 0,45 & 0,00 & 0,00 & 0,00 & 0,50 & 0,00 \\
\hline Viasio para pedestres & 0,25 & 0,25 & Vazio & 0,25 & 0,00 & 0,25 & 0,25 \\
Vias com calçadas & 0,90 & 0,94 & 0,91 & 1,00 & 0,07 & 0,25 & Vazio \\
\hline $\begin{array}{c}\text { Distância de viagem } \\
\text { Tempo de viagem }\end{array}$ & 0,95 & Vazio & 0,63 & Vazio & Vazio & 0,00 & 0,58 \\
Número de viagens & 1,00 & Vazio & 0,96 & Vazio & Vazio & 0,50 & 1,00 \\
$\begin{array}{c}\text { Ações para redução do } \\
\text { tráfego motorizado }\end{array}$ & 0,72 & 0,85 & 0,64 & Vazio & Vazio & 0,69 & 0,60 \\
\hline Domínio & 1,00 & 0,50 & 0,25 & 0,25 & 0,25 & 0,00 & 0,00 \\
\hline
\end{tabular}

Fonte: Abdala (2013), Assunção (2012), Costa (2008), Miranda (2010), Pontes (2010).

O indicador Extensão e conectividade de ciclovias apresenta valores semelhantes e baixos em todos os municípios dispostos incluindo Sinop, representando a falta de atenção dada pelo poder público às vias cicláveis, oferecendo pequenas redes para circulação de bicicletas.

Sobre a frota de bicicletas, apenas Curitiba apresentou informação de pesquisa institucional. Goiânia, assim como Sinop, apresentou como fonte do dado uma estimativa da administração municipal, porém obtendo valor baixo, enquanto Sinop, assim como Curitiba, teve valor máximo de score neste indicador, devido ao grande número de bicicletas em circulação, representando um grande uso do modal cicloviário. 
O Estacionamento de bicicletas apresenta baixos valores para os municípios, com quatro obtendo pontuação zero. Sinop se encontra entre estes, o que mostra que não há uma preocupação em integrar os modais de transporte, trazendo obstáculos a população.

No tema Vias para pedestres, o indicador homônimo, único calculado em Sinop, apresenta os mesmos valores de outras quatro cidades. A pontuação destes municípios indica a baixa extensão e conectividade ou inexistência de vias próprias ou preferenciais para pedestres, assim como ocorre com as ciclovias, desencorajando o uso de modos não motorizados. As vias com calçadas configuraram um indicador vazio para Sinop, pela ausência de dados confiáveis para cálculo, porém a alta média das pontuações dos outros municípios, assim como a existência de calçadas em boa parte da cidade, leva a constatação de que o indicador referente contribuiria positivamente para o índice do domínio se fosse possível o seu cálculo.

Os indicadores Distância de viagem, Tempo de viagem, e Número de viagens são relacionados a dados de pesquisas origem/destino. Dentre os municípios acima relacionados, apenas São Carlos, Uberlândia e Brasília apresentam tal levantamento, permitindo o cálculo dos scores, com Goiânia possuindo uma pesquisa de mobilidade urbana com o número de viagens. Para Sinop, as estimativas adotadas forneceram a base necessária para cálculo por meio de adaptação e as pontuações obtidas aproximam-se da média das outras cidades, visto que Sinop apresenta score máximo em Tempo de viagem devido a não haver ainda extensão viária que seja grande o suficiente para levar a tempos elevados, assim como são raras grandes distâncias de viagem pelo mesmo motivo, porém com score menor. A pontuação do número de viagens reflete menor mobilidade da população sinopense comparada às dos demais municípios.

Além de Sinop, apenas Brasília não apresenta nenhuma ação para redução do tráfego motorizado, configurando pontuação zero, o que indica que há uma disparidade entre a preocupação sobre o crescimento da frota circulante nos outros municípios e Sinop. Falta ao poder público criar medidas de controle para equilibrar a frota no município de modo a não prejudicar a mobilidade.

A Figura 4 exibe um comparativo entre os índices encontrados nas cidades utilizadas como referência, nos domínios abordados nesta pesquisa.

Figura 4 - Comparativo entre os Domínios Aspectos Ambientais e Modos não Motorizados nas cidades

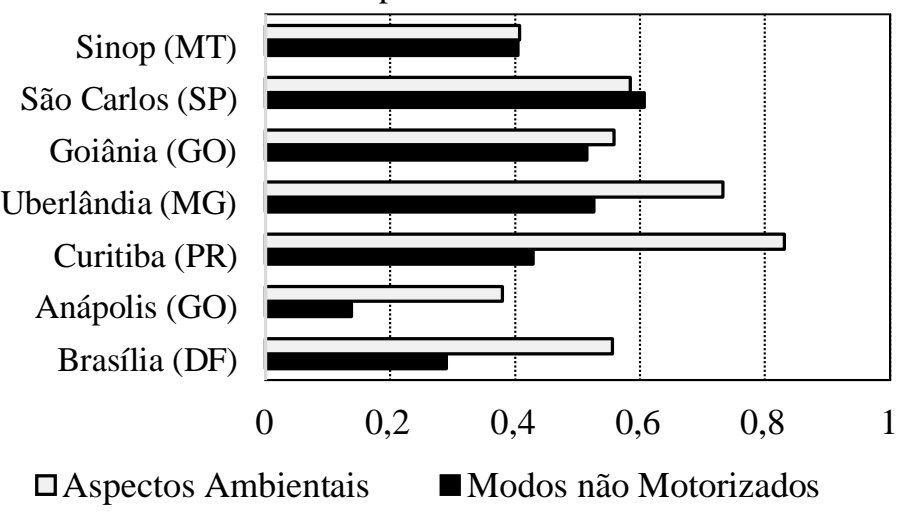

\subsection{Considerações sobre a relação dos resultados com a metodologia}

De um modo geral, os resultados comprovam que a metodologia apresenta alguns aspectos a melhorar e um aprimoramento em função dos trabalhos realizados sobre o IMUS. Observa-se atualmente que alguns indicadores têm grande influência, sendo que são de solução simples como por exemplo, o estacionamento de bicicletas que sozinho não comprova a integração entre modais de transporte e é de fácil instalação para melhorar o score. Por outro lado, alguns indicadores que envolvem estudos complexos, como a população exposta ao ruído de tráfego, tem peso muito semelhante ao de indicadores mais simples, mesmo que para este 
seja necessário um mapeamento de ruído da cidade, o qual representa uma grande influência na qualidade de vida e grande consequência do tráfego motorizado.

Além da distribuição de pesos, outro ponto a ser observado é o do método de cálculo em si dos indicadores, que não apresenta padrões e, em alguns casos, apresenta certa ineficiência, como no caso do consumo de combustível, onde para uma maior precisão do indicador, veículos e combustíveis mais pesados também deveriam ser considerados de certa forma, devido a sua contribuição negativa para a qualidade do ar.

\section{CONCLUSÃO}

Obteve-se o IMUS setorial de 0,407 para o domínio Aspectos Ambientais e de 0,405 para o domínio Modos não Motorizados no município de Sinop. Dentro da escala do índice, entre 0 e 1 , os dois domínios apresentaram pontuação abaixo do valor intermediário $(0,50)$, configurando uma influência negativa sobre a mobilidade urbana, porém com provável evolução devido a obras e implementações previstas para o município, que podem representar melhorias no índice a médio prazo.

Sinop apresenta obstáculos na mobilidade urbana referentes aos modos não motorizados: o grande número de bicicletas e pedestres no município que não possui infraestrutura suficiente para circulação. Essa falta acarreta em impactos negativos, como maior circulação de diferentes modos no mesmo espaço de maneira inadequada, podendo resultar em maior número de congestionamentos e acidentes.

Há também a falta de políticas voltadas a mobilidade urbana no geral e também aliada a sustentabilidade, uma vez que não existe a implementação de medidas de controle de impactos ambientais relativos aos transportes. $\mathrm{O}$ uso de modos não motorizados e transporte público, tende a levar a um menor número de automóveis nas vias, reduzindo o consumo de combustíveis, emissões de gases e níveis de ruído, proporcionando maior bem-estar à população.

A ausência de dados confiáveis para tornar possível uma avaliação adequada da mobilidade por meio do IMUS e/ou outras ferramentas, constitui um obstáculo em formar referências para o poder público do município que possam auxiliar no desenvolvimento do Plano de Mobilidade Urbana. O IMUS em si apresenta necessidade de melhorias na metodologia para poder atingir uma maior precisão do cenário da mobilidade urbana.

Para trabalhos futuros, assim como medidas que possam apresentar soluções, sugere-se a formação de um instituto responsável por monitorar a mobilidade urbana no município por meio de pesquisas e levantamentos; o desenvolvimento e aplicação de políticas exigentes para regulamentação da frota quanto a poluição; e a realização em curto prazo de uma pesquisa origem/destino, configuram alternativas para o aprimoramento da base de dados da mobilidade e maior efetividade da aplicação de ferramentas de avaliação. A periodicidade da realização de pesquisas como o cálculo do IMUS tem a função de auxiliar cidades como Sinop em seu desenvolvimento geral.

\section{REFERÊNCIAS}

ABDALA, Ivanilde Maria de Rezende. Aplicação do Índice de Mobilidade Urbana Sustentável (IMUS) em Goiânia. 2013. Dissertação (mestrado). 203f. Pós graduação em Desenvolvimento e Planejamento Territorial, Pontifícia Universidade Católica de Goiás, 2013.

AGÊNCIA NACIONAL DO PETRÓLEO, GÁS NATURAL E BIOCOMBUSTÍVEIS. Vendas Anuais de Etanol Hidratado e Derivados de Petróleo por município. Planilhas. 2013. Disponível em: <http://www.anp.gov.br/?pg=78003\&m=\&t1=\&t2=\&t3=\&t4=\&ar=\&ps=\&1445564510551> 
ASSOCIAÇÃO BRASILEIRA DE NORMAS TÉCNICAS. NBR 10151: acústica - avaliação do ruído em áreas habitadas, visando o conforto da comunidade - procedimento. Rio de Janeiro, 2000 .

ASSOCIAÇÃO NACIONAL DE TRANSPORTES PÚBLICOS. Sistema de Informações da Mobilidade Urbana da ANTP: relatório final 2013. São Paulo, 2015. Relatório.

ASSUNÇÃO, M. A. D. Indicadores de mobilidade urbana sustentável para a cidade de Uberlândia, MG. 2012. Dissertação (mestrado). 148f. Pós graduação em Engenharia Civil, Universidade Federal de Uberlândia, 2012.

BERRETTINI, R.; SILVA, A. N. R. e SILVEIRA, A. Levantamento do Nível de Ruído dos Veículos nas Proximidades da Avenida São Carlos: Utilizando um SIG para Avaliar Níveis de Ruído de Tráfego em uma Cidade Média. In: COBRAC - Congresso Brasileiro de Cadastro Técnico Multifinalitário, 1998, Florianópolis. Anais ... Florianópolis: UFSC, 1998.

BRASIL. Lei ${ }^{\circ}$ 12.587, de 3 de janeiro de 2012. Institui as diretrizes da Política Nacional de Mobilidade Urbana e dá outras providências. Casa Civil, Brasília, DF, 3 jan. 2012.

COMPANHIA AMBIENTAL DO ESTADO DE SÃO PAULO. Emissões veiculares no estado de SãoPaulo 2014. São Paulo, 2014. Relatório. Disponível em: <http://veicular.cetesb.sp.gov.br/relatorios-e-publicacoes/>

COSTA, Marcela da Silva. Um Índice de Mobilidade Urbana Sustentável. 2008. Tese (Doutorado). 274f. Pós graduação em Engenharia Civil, Escola de Engenharia de São Carlos, Universidade de São Paulo, São Carlos, 2008.

DEPARTAMENTO NACIONAL DE TRÂNSITO. Frota de Veículos - Quantidade de veículos por município (Dezembro de 2014). Planilhas. 2014. Disponível em: <http://www.denatran.gov.br/frota2014.htm>

MORAES, João Maria de. Transporte coletivo e sustentabilidade - Empresa de ônibus Rosa LTDA. Entrevista. Sinop, 2015.

EUROPA. Sínteses da legislação da UE. Proposta COM/2007/0856. Disponível em: <http://eur- lex.europa.eu/legal-content/PT/TXT/?uri=CELEX:5200 7PC0856>.

INSTITUTO BRASILEIRO DE GEOGRAFIA E ESTATÍSTICA. Sinopse do censo 2010 Densidade demográfica preliminar $\left(\mathbf{h a b} / \mathbf{k m}^{2}\right)$. Disponível em: <http://www.censo2010.ibge.gov.br/sinopseporsetores/?nivel=st>

Estimativas de população para $1^{\circ}$ de julho de 2013. Disponível em: <ftp://ftp.ibge.gov.br/Estimativas_de_Populacao/Estimativas_2013/populacoes_estimativas_ municipios_TCU_31_10_2013.pdf>

Estimativas de população para $1^{\circ}$ de julho de 2014. Disponível em: <ftp://ftp.ibge.gov.br/Estimativas_de_Populacao/Estimativas_2014/estimativas_2014_TCU.p df $>$ 
MCIDADES. Política Nacional de Mobilidade Urbana Sustentável. Brasília: Ministério das Cidades. Secretaria Nacional de Transporte e da Mobilidade Urbana (SeMOB), 2004.

MENDONÇA, A.B.D; SURIANO, T.M; SOUZA, L.C.L; VIVIANI, E. MEDIÇÕES ACÚSTICAS: variação da geometria da via urbana e tempo de amostragem. In: III SIMPGEU - Simpósio de pós graduação em Engenharia Urbana, 2012. Anais ... Maringá: UEM, 2012.

MIRANDA, Hellem de Freitas. Mobilidade urbana sustentável e o caso de Curitiba. 2010. Dissertação (mestrado). 160f. Pós graduação em Engenharia de Transportes, Escola de Engenharia de São Carlos, Universidade de São Paulo, 2010.

MORAIS, Talita Caetano de. Avaliação e seleção de alternativas para promoção da mobilidade urbana sustentável - o caso de Anápolis, Goiás.2012. Dissertação (mestrado). 141f. Pós graduação em Engenharia Civil, Escola de Engenharia de São Carlos, Universidade de São Paulo, 2012.

NETO, N. C.; ROZA, A. E. D. Análise de nível de serviço e geometria de rótula urbana no município de Sinop-MT. Sinop, MT: Universidade do Estado de Mato Grosso, 2015.

PONTES, Taís Furtado. Avaliação da mobilidade urbana na área metropolitana de Brasília. 2010. Dissertação (mestrado). 250f. Pós graduação em Arquitetura e Urbanismo, Faculdade de Arquitetura e Urbanismo, Universidade de Brasília, 2010.

FERRI, R. C. R. Entrevista com a Secretária de Meio Ambiente (gestora) Rosimari Cristina Ribeiro Ferri. Entrevista. 2015.

FRANKE, I. M. Entrevista com a Secretária de Trânsito (gestora) Ivete Mallmann Franke. Entrevista. 2015 